\title{
Fracture toughness evaluation of bituminous binders at low temperatures
}

\author{
M. Bueno $\cdot$ M. Hugener $\cdot$ M. N. Partl
}

Received: 24 January 2014 / Accepted: 8 July 2014/Published online: 16 July 2014

(C) RILEM 2014

\begin{abstract}
When asphalt roads turn brittle at low temperatures, they are no longer able to relax completely from traffic induced stresses and may also suffer damage through crack initiation and propagation. In order to avoid early structural damages, the bituminous binders must be selected very carefully. However, conventional test methods for assessing performance of bituminous binders at low temperatures are often unsatisfactory reliable, in particular in case of polymer modified bituminous binders. In this study, an alternative experimental method based on fracture mechanical principles was performed on pre-notched specimens in the brittle state inside a cooling media. This fracture toughness test was evaluated in terms of its suitability for distinguishing different types of polymer modified and unmodified bituminous binders. In addition, the feasibility to evaluate different ageing states was also analysed by testing samples after artificial short-term and long-term ageing procedures. The repeatability
\end{abstract}

M. Bueno $(\square) \cdot$ M. Hugener · M. N. Partl

Empa, Swiss Federal Laboratories for Material Testing and Research, Ueberlandstr. 129, 8600 Duebendorf, Switzerland

e-mail: moises.bueno@empa.ch

M. Bueno

UCLM, Universidad de Castilla-La Mancha, Avda. Camilo José Cela, 13071 Ciudad Real, Spain

M. N. Partl

KTH, Royal Institute of Technology, Brinellväge 23, 10044 Stockholm, Sweden obtained from the experimental results showed that the fracture toughness test is a suitable candidate for being introduced in a standardization framework.

Keywords Fracture toughness test · Low temperature behaviour - Polymer modified bituminous binder - Thermal cracking - Asphalt road - Bitumen

\section{Introduction}

In asphalt roads, bottom-up cracking is mostly caused by insufficient dimensioning as well as lack of adhesion between layers. On the other hand, crack formation from the top of the road primarily results from tyre-road interactions, which produce repeated horizontal tension stresses under wheel loads [1]. In cold regions (sudden low temperature cracking) and in areas which experience large repeated extremes in daily temperatures (thermal fatigue cracking) [2] crack formation can be intensified by combining the static tension components from thermal contraction and incomplete relaxation with the tyre-induced stresses. Moreover, the risk of cracking is increased by numerous imperfections and defects that are common in pavement structures due to construction or a combination of aging and operation induced distress. It is around these imperfections that thermal stresses concentrate allowing crack initiation and/or crack propagation when the tensile strength of the asphalt mixture is exceeded [3]. 
The propagation of a crack through an asphalt pavement depends directly on the mechanical properties of the binder. The crack path is mostly observed inside the bitumen film around the aggregates [4]. When the pavement cools, the bituminous binder slowly transforms from a viscoelastic ductile into an elastic brittle material. Initially, at warm temperatures, the binder is soft enough for any shrinkage stress to relax through viscous flow but later, at some colder temperature, it stiffens making the relaxation from thermal stresses more difficult. The mechanical behaviour of bitumen at low temperature is related to its chemical composition which may be defined by the so-called SARA fractions. Asphaltenes and resins, i.e. the fractions with higher molecular weights, provide the major part of the elastic behaviour, whereas aromatics and saturates, i.e. the fractions with low molecular weight and low glass transition temperatures, are related to the viscous behaviour. In order to improve the performance of bitumen, several types of polymers have been used as modifiers [5]. The final properties of the polymer modified bituminous binder depend on the morphology, polymer content, particle size and chemo-physical material compatibility. Basically, the polymer is swollen by some fractions of the bitumen, mainly by the resins, aromatics and saturates (maltenes), artificially enriching the asphaltene fraction by a "physical distillation" of the lighter species from the original bitumen, leading to a toughened binder matrix.

Since asphalt pavements start to experience cracks when binders reach the brittle state during cooling, efforts in its study were concentrated on the evaluation of the binder's fracture behaviour as described in the literature [6]. However, the conventional assessment of the low temperature properties of bituminous binders is often insufficient and repeatedly results in costly misjudgements and damaged roads. Moreover, the standardized test method "Fraass breaking point" [7] shows low reproducibility, in particular with special and polymer-modified binders, and does not provide fundamental mechanical characteristics. Similar holds for another technological test, the Moriyoshi breaking point [8]. Some years ago, the determination of the flexural creep stiffness with the bending beam rheometer (BBR) was proposed [9]. As this is a creep test, the expectations have only partly been satisfied. It is objected that the BBR test stays in the viscoelastic domain and therefore it is not able to accurately assess low temperature failure behaviour, except for unmodified bitumen [10]. Since the cracking properties are also dependent on the microstructure (nature and size of polymer inclusions), the linear viscoelastic properties cannot always differentiate between pure and modified binders. For these reasons, fracture mechanical principles appear necessary to understand the cracking phenomena of all types of bituminous binders at low temperature. So far, experimental tests such as the compact tension test [11] and the double edge-notched tension test [12] have been also used with different success for assessing the low temperature behaviour of bituminous binders. Other tests, like the double torsion test have been applied to mastic asphalt, but it could also be suitable for binder testing alone [13].

Fracture toughness provides a measure of resistance to failure in the presence of severe tensile constraints and sharp cracks. As this property is independent of sample size and geometry, it is generally considered useful for initial type testing and specification verification [14]. This is particularly true for notched specimen fracture tests at low temperatures. The fracture mechanics approach accounts for the fact that a pre-existing crack significantly changes the stress field in the material making it effectively weaker [15-17]. Thus, a newly developed Fracture Toughness Test (FTT) similar to those used for metals, ceramics and polymer materials, has been adapted and considered as possible alternative test method for determining low temperature properties of bituminous binders [6]. Since the calculation of fracture toughness and fracture energy as material parameters is only applicable in the linear-elastic domain and bituminous binders at low temperatures do not always stay in this domain, it was decided to focus also on determining the so-called fracture toughness temperature $\left(T_{\mathrm{FT}}\right)$ at which the transition from ductile to brittle state is assumed to occur.

Recent results from an international round robin test carried out between eight different laboratories (including Empa) have shown that this FTT is a promising tool for characterising the low temperature behaviour of bituminous binders [18]. The scope of this work was to evaluate the FTT method for a large range of different binders, unmodified and modified, hard and soft bituminous binders based on their low temperature performances obtained from fracture toughness tests. Moreover, the feasibility of the FTT 
Table 1 Properties of the bituminous binders

\begin{tabular}{|c|c|c|c|}
\hline Binder type & $\begin{array}{l}\text { Penetration } \\
(0.1 \mathrm{~mm})\end{array}$ & $\begin{array}{l}\text { Softening } \\
\text { point } \\
\left({ }^{\circ} \mathrm{C}\right)\end{array}$ & Characteristics \\
\hline Bitumen 10/20 & 16 & 62.6 & Neat bitumen \\
\hline Bitumen 35/50 & 42 & 57.2 & Neat bitumen \\
\hline $\begin{array}{l}\text { Bitumen } \\
180 / 200\end{array}$ & 178 & 40.6 & Neat bitumen \\
\hline PmB 50/70-53 & 48 & 59.0 & $\begin{array}{l}\text { Polymer modified } \\
\text { bitumen }\end{array}$ \\
\hline PmB 25/55-65 & 48 & 92.5 & $\begin{array}{l}\text { Polymer and wax } \\
\text { modified } \\
\text { bitumen }\end{array}$ \\
\hline PmB 90/150-60 & 119 & 73.6 & $\begin{array}{l}\text { Polymer modified } \\
\text { bitumen }\end{array}$ \\
\hline
\end{tabular}

to distinguish between different ageing states was analysed with this study.

\section{Experimental}

\subsection{Materials}

Three unmodified and three polymer modified bituminous binders covering a wide spectrum of characteristics have been used (Table 1). Samples were provided by commercial suppliers. Thus, details related to binder formulation and modification (i.e. polymer type and polymer content) are unknown. Moreover, laboratory aged samples were tested to analyse the influence of artificial ageing on the low temperature performance of different binders. For that, the bituminous binders were subjected to shortterm RTFOT (Rolling Thin Film Oven Test) [19] and long-term PAV (Pressure Ageing Vessel) ageing [20] procedures prior to testing.

\subsection{Fracture toughness test (FTT)}

\subsubsection{Test procedure}

The fracture toughness test (FTT) is defined in the European technical specification CEN/TS 15963:2010 [21], which has been approved for provisional application. It is based on a three point bending test where the test sample is a beam with a thin notch in the middle (see detailed specimen preparation below).
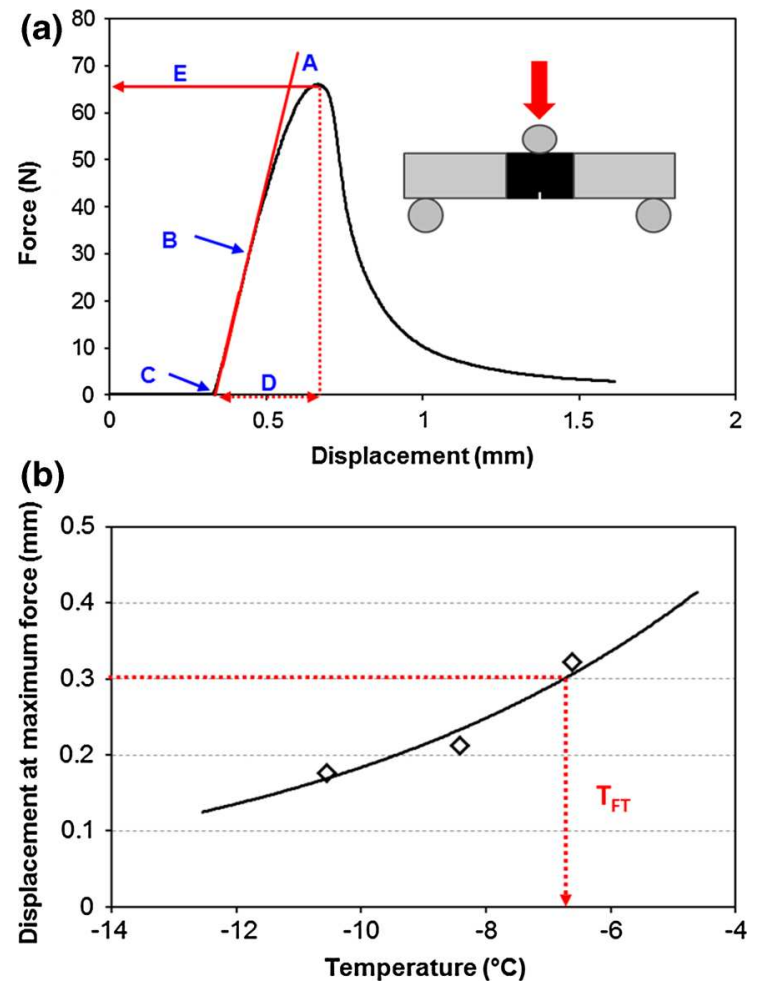

Fig. 1 Displacement curve from a fracture toughness test and scheme of bending rig (a). (A) Tangent at the $(B)$ inflection point of the force versus displacement curve, $(C)$ zero point and $(D)$ displacement at $(E)$ maximum force. Calculation of the fracture toughness temperature $\left(T_{\mathrm{FT}}\right)(\mathbf{b})$

The test is carried out in a temperature controlled cooling bath.

After the beam has been conditioned at the test temperature in a cooling bath, it is properly placed on the bending rig with the notch facing downwards and aligned with the loading shaft. Next, a vertical loading is applied with a constant displacement rate of $0.01 \mathrm{~mm} / \mathrm{s}$ on the middle of the upper side of the sample until failure occurs. The force is recorded versus displacement at different test temperatures (Fig. 1a). In order to accept the failure as brittle, the displacement at maximum force has to be below $1 \mathrm{~mm}$. At least three beams must be tested at the same temperature and the average calculated. The fracture toughness temperature $\left(T_{\mathrm{FT}}\right)$ of a bituminous binder is defined as the temperature at which the displacement at maximum force is $0.3 \mathrm{~mm}$ (Fig. 1b).

A more detailed description of the experimental procedure can be found in the technical specification 

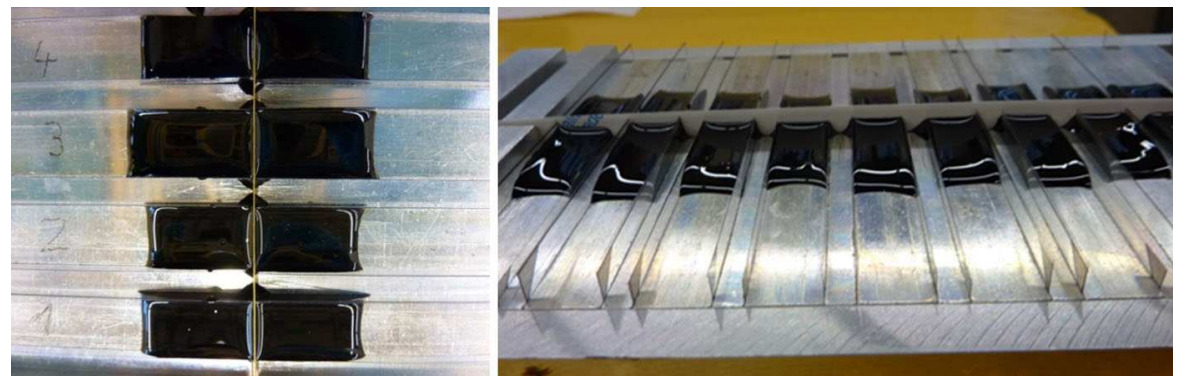

Fig. 2 Assembling details of the notched specimen preparation. Upper (left) and lateral (right) view

[21] in order to achieve a complete understanding of the fracture toughness test.

\subsubsection{Specimen preparation}

Preparation and conditioning of the specimens are important steps in testing the behaviour of bituminous binders and have direct influence on the accuracy and repeatability of the results. Here, an aluminium mould designed and manufactured by IFSTTAR (Nantes, France) assembled by different parts was used to prepare series of ten beams at the same time (Fig. 2). Each test specimen is composed of two aluminium inserts with a pre-notched piece of bitumen. The calculus of the different fracture parameters for this non-homogenous geometry was validated in a previous work [22] since in three point bending tests these parameters are usually associated with homogenous material tests. The notch geometry is crucial for the fracture initiation: the narrower the notch, the more concentrated is the stress for the crack initiation at the notch. The mode of loading considered here is mode I (i.e. tension). Originally the notch (5 mm depth) was formed by placing two thin films of polytetrafluoroethylene (PTFE) into the sample to make a very narrow vertical notch. This material is very soft and flexible and it had to be well tightened to avoid any undulation while pouring bitumen into the mould, what actually has a major effect on the repeatability of the results. For these practical reasons, in this study the PTFE double film was replaced by a double film of $0.150 \mathrm{~mm}$ thick coated silicone paper (Hexis, Germany) glued together with a small amount of silicon grease (Molikote ${ }^{\circledR}$ Multilub, USA). The different aspects of sample preparation have been previously investigated in more detail in order to improve the experimental procedure [23].

\subsubsection{Equipment}

An electromechanical testing system (Instron ${ }^{\circledR} 1122$, UK) has been used to apply the bending at constant deflection speed. A $0.5 \mathrm{kN}$ load cell (MTS, Switzerland) and a LVDT transducer (HBM, Germany) have been separately installed for the accurate measurement of the force and the deflection. Data acquisition was accomplished with a Spider 8 System and Catman ${ }^{\circledR}$ software (HBM, Germany). Following the specification [21], the bending rig was placed inside a liquid bath with ethanol (purity $99 \%$ ) as cooling fluid, being circulated between the cooling unit (Huber miniStat ${ }^{\circledR}$ cc2, Germany) and the test bath at testing temperature. In this study, the use of ethanol as cooling fluid and its possible influence on the results have been considered since other authors [24] reported lower strength values in comparison to other cooling medium (i.e. air or potassium acetate) and claimed that organic solvents can affect fracture mechanical properties and therefore repeatability.

\subsection{Fraass breaking point}

The determination of the Fraass breaking point is a conventional method used to evaluate the performance of bituminous binders at low temperature. Following the standard [7], the test was carried out on a manual apparatus where a sample of bituminous binder was applied to a metal plate at an even thickness being submitted to a constant cooling rate and flexed repeatedly until the binder layer breaks; the temperature at which the first crack appears was reported as the Fraass breaking point. It is commonly acknowledged that this method presents a poor reproducibility due to the difficulty to control the test parameters and visualize the crack mainly in case of special and 
Table 2 Fracture toughness temperatures obtained for different types of bituminous binders and ageing states

\begin{tabular}{lrrrlll}
\hline & \multicolumn{7}{l}{ Fracture toughness temperature $\left({ }^{\circ} \mathrm{C}\right)$} \\
\cline { 2 - 7 } & $10 / 20$ & $35 / 50$ & $180 / 200$ & \multicolumn{1}{l}{ PmB } & PmB & \multicolumn{1}{l}{ PmB } \\
& & & & $50 / 70-53$ & $25 / 55-65$ & $90 / 150-60$ \\
\hline Original & $\mathbf{2 . 4}$ & $\mathbf{- 6 . 7}$ & $\mathbf{- 1 4 . 5}$ & $\mathbf{- 7 . 2}$ & $\mathbf{- 1 6 . 5}$ & $\mathbf{- 2 4 . 5}$ \\
$r$ & 0.7 & 0.3 & 0.2 & 0.4 & 1.4 & 1.3 \\
RTFOT & $\mathbf{6 . 9}$ & $\mathbf{- 3 . 5}$ & $\mathbf{- 1 3 . 4}$ & $\mathbf{- 5 . 6}$ & $\mathbf{- 9 . 4}$ & $\mathbf{- 1 7 . 8}$ \\
$r$ & 1.8 & 0.5 & 1.2 & 0.3 & 1.6 & 0.4 \\
PAV & $\mathbf{1 0 . 1}$ & $\mathbf{3 . 8}$ & $\mathbf{- 7 . 4}$ & $\mathbf{- 1 . 2}$ & $\mathbf{- 3 . 8}$ & $\mathbf{- 1 2 . 8}$ \\
$r$ & 1.0 & 0.6 & 1.1 & 0.7 & 0.8 & 0.9 \\
\hline
\end{tabular}

Bold is used to highlight the different values of Fracture Toughness Temperature $\left(T_{\mathrm{FT}}\right)$ and to distinguish them from the values of repeatability (r)

polymer modified binders. Measurements were carried out in order to compare the results obtained from different tests at low temperature.

\section{Results and discussion}

\subsection{Fracture toughness temperature. General analysis}

In this part of the work the fracture toughness temperatures related to different types of bituminous binders before and after different ageing procedures are presented (Table 2). An analysis of the results was carried out, comparing the low temperature behaviour of modified and un-modified bitumen. The repeatability for the procedure defined in the international round robin test performed [17] is also presented. As an interpolation fitting procedure is subjected to uncertainty, in this FTT, the fracture toughness temperature, which corresponds to a displacement at break, is also determined with certain inaccuracy. In the round robin test [18] the estimate for repeatability was given as $r=3{ }^{\circ} \mathrm{C}$ considering the differences between laboratories in terms of cooling systems. In our study, it can be observed that the values obtained are mostly below $2{ }^{\circ} \mathrm{C}$ without any defined trend in relation to the type and properties of the binders as well as their ageing state. This fact corroborates the accuracy of the fracture toughness test for assessing low temperature properties of bituminous binders as well as the low influence of the ethanol as cooling fluid on the repeatability of the results.

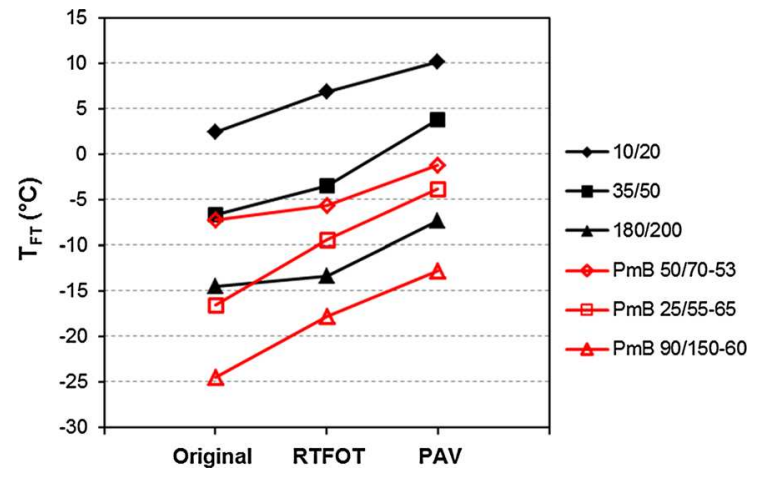

Fig. 3 Influence of the ageing on fracture toughness temperature $\left(T_{\mathrm{FT}}\right)$ for different bituminous binders

The ranking related to the fracture toughness temperature of the different bituminous binders and its evolution with the ageing procedures is presented in Fig. 3. In this figure, it can be observed that, in its original state, the polymer modified binder PmB 90/150-60 presented the lowest fracture toughness temperature. This means that this binder reached the ductile to brittle transition at very low temperatures, improving its mechanical performance against fracture. Next, it can be considered that the unmodified bitumen 180/200 as well as the polymer and wax modified binder PmB 25/55-65 had also a good performance, presenting fracture toughness temperatures around $-10{ }^{\circ} \mathrm{C}$. On the other hand, it was found that the hardest unmodified bitumen 10/20 reached the brittle state even at positive temperatures. This fact will be analysed in the next section where the low temperature performance is correlated with standard properties of the binders like penetration and softening point.

Attending to the evolution of the low temperature performance with ageing, it seems clear that this behaviour changed after the different treatments. During service life, the asphalt pavement ages and the brittleness of the material increases due to physicochemical changes in the binder [2, 25]. The most important mechanism related to bitumen ageing is the oxidation of the bitumen components, generally producing functionalities with higher polarity, increasing the content of asphaltenes and thus, increasing the stiffness and the brittleness. This is a clearly demonstrated for all the types of binder after short-term ageing (RTFOT) where the fracture 
toughness temperature can increase up to $7{ }^{\circ} \mathrm{C}$. After long-term ageing in the PAV, the fracture toughness temperature has increased up to $10{ }^{\circ} \mathrm{C}$. However, the performance ranking found after the two ageing procedures is the same as in the original state. It is interesting to remark that the $\mathrm{PmB} 50 / 70-53$, is the binder which is less influenced by ageing. This polymer modified binder presented only $6{ }^{\circ} \mathrm{C}$ higher fracture toughness temperature after long-term ageing. From a general view, different trends can be drawn depending on the type of the binder. The trend is linear for polymer modified binders, with the same increase of the fracture toughness temperature after RTFOT and PAV ageing. On the other hand, the unmodified bituminous binders seem to be less affected by shortterm ageing compared to long-term ageing.

\subsection{Correlation with penetration and softening point}

All parameters characterizing the mechanical performance of a bituminous binder are related to its internal structure and chemical properties. Therefore, in this section, correlation between fracture toughness temperature and other physical properties (softening point and penetration) is analysed.

Penetration [26] is a property used to classify bitumen by its hardness and consistency. It was designed to assess the suitability under different climatic conditions and to define performance characteristics of bitumen that will be required in construction works. For example, a hard binder is not recommended for cold areas. Figure 4 shows the correlation between fracture toughness temperatures and penetration values for the different bituminous binders in its original state before ageing. In this figure it can be observed that hard bituminous binders show poor low temperature behaviour due to an earlier transition to the brittle state when the material is cooling down. In general, binders with higher penetration tend to lower fracture toughness temperatures; however, the correlation is poor. The unmodified binder with the highest penetration presented a fracture toughness temperature lower than $-15{ }^{\circ} \mathrm{C}$ in the original state. It is remarkable that almost the same value was obtained for the PmB 25/55-65 with a significant lower penetration value. This fact clearly shows the improvement of low temperature performance achieved by polymer modification of the bitumen.

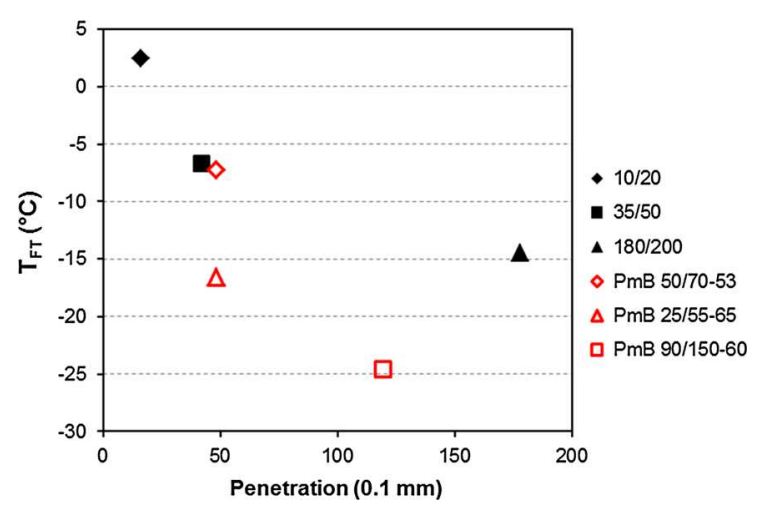

Fig. 4 Fracture toughness temperature $\left(T_{\mathrm{FT}}\right)$ in relation to penetration

On the other hand, the softening point [27] refers to the temperature at which the bitumen attains a particular degree of softening. This property could be important for low temperature performance as well as mixing and construction of an asphalt road. Figure 5 presents the correlation between fracture toughness temperatures and softening points of the different binders before and after ageing. Generally, both the softening point and the fracture toughness temperature increase after ageing. Considering unmodified binders, despite losing performance properties with ageing, a lower softening point appears to be followed by a lower fracture toughness temperature. However, it is difficult to find any general tendency related to the binder softness due to internal structure differences of the binders. It seems clear that polymer modification reduces the fracture toughness temperature and attenuates the thermal susceptibility [4]. Thermal stresses may relax during cooling thanks to the effect of the polymer modification. However, this advantage depends on the morphology of the polymer modified binder (e.g. type and amount of polymer, particle size or state of dispersion) [5]. Nevertheless, the results of this study clearly showed that the fracture toughness test is able to distinguish this difference in the low temperature behaviour and corroborates what has been shown in the asphalt roads.

\subsection{Correlation fracture toughness temperature- Fraass breaking point}

The calculation of the Fraass breaking point [7] is the standard method for evaluating the performance of 

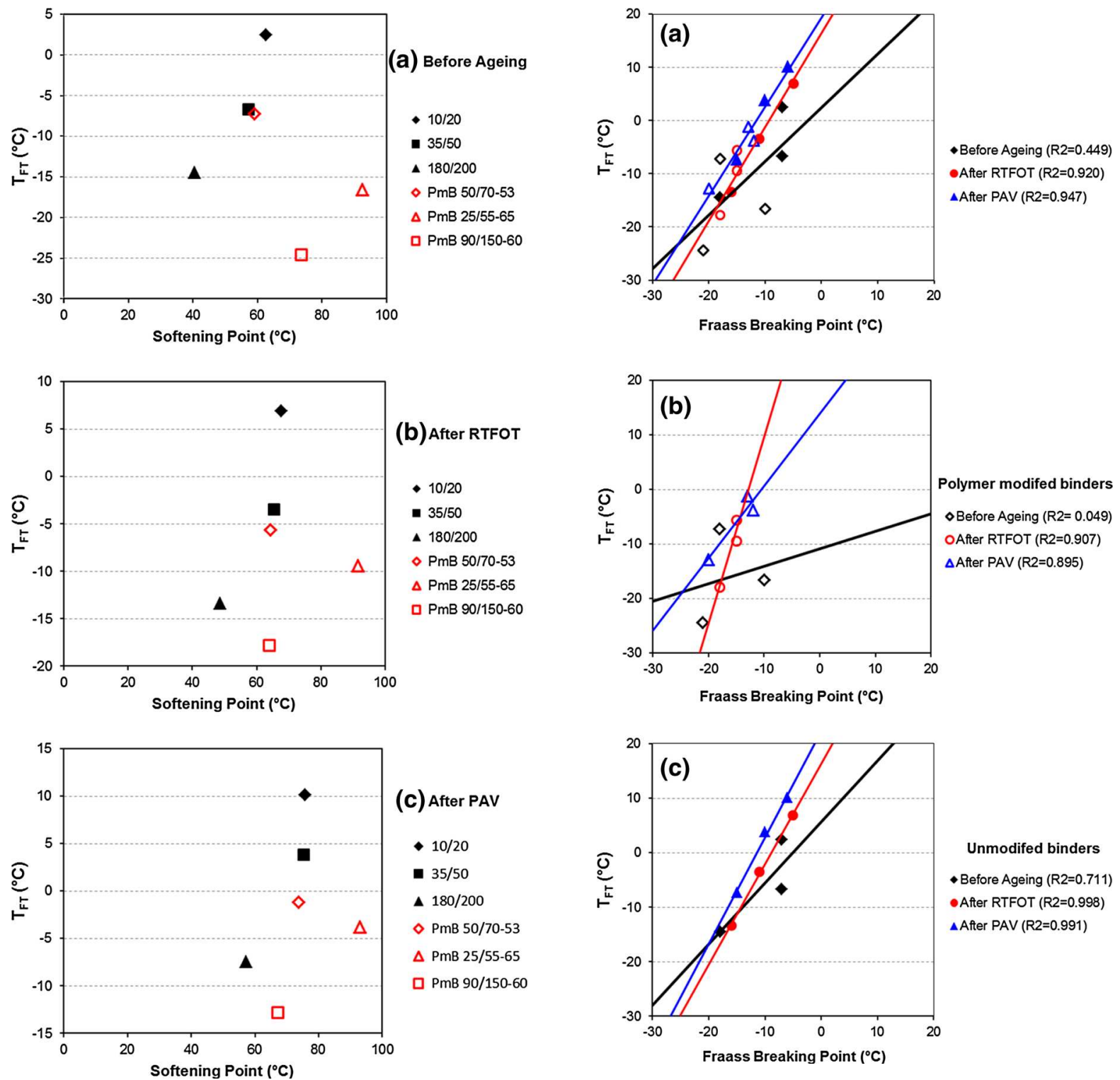

Fig. 5 Fracture toughness temperature $\left(T_{\mathrm{FT}}\right)$ in relation to softening point before ageing (a), after short term (RTFOT) (b) and long term (PAV) (c) ageing procedures

bituminous binders at low temperatures but, it is known for its poor reproducibility. Therefore, a comparison between the fracture toughness temperatures and the Fraass breaking points was performed in search for alternatives. Figure 6 shows the linear correlation between the two parameters before and after the different ageing procedures.

Figure 6 a exhibits the correlation of all bituminous binders for all ageing states. It can be seen that the

Fig. 6 Correlation between fracture toughness temperature $\left(T_{\mathrm{FT}}\right)$ and Fraass breaking point at different ageing states. General (a), polymer modified bitumen (b) and unmodified bitumen correlations (c)

differences could reach values above $10{ }^{\circ} \mathrm{C}$. Correlation is low for the binders before ageing $\left(R^{2}=0.449\right)$ but improves after RTFOT $\left(R^{2}=0.920\right)$ and even more after PAV $\left(R^{2}=0.947\right)$. The correlations lines of RTFOT and PAV are parallel indicating a similar change in Fraass and FTT properties by ageing. For most specimens, the Fraass breaking point was lower than the fracture toughness temperature leading to an overestimation of the low temperature behaviour of 
the binders. This is a general fact that did not seem to have any relation to the type of the bitumen or its aging state but was most probably caused by the clear experimental differences between the two tests, such as cooling system or stress application. It is necessary to keep in mind that the notched specimen used in the fracture toughness test has certainly intensified the tension stress at the crack tip easing the propagation of the fracture at higher temperature when the specimen was assumed to reach the brittle state.

Considering just the temperatures from polymer modified binders (Fig. 6b), it can be seen that this linear correlation is worse than for the unmodified ones (Fig. 6c). This observed fact matches with the problems with Fraass breaking point test when assessing polymer modified binders.

\subsection{Analysis of FTT parameters: maximum force, work and stiffness}

The data obtained from the fracture toughness tests allow the calculation of additional characteristic values which depend on the type of bituminous binder such as the work carried out until the onset of the fracture that corresponded to the area under the forcedisplacement curve until the highest force measured. Other parameters are the maximum force reached considered as the onset of the crack propagation and the stiffness at test temperature calculated as the tangent of the force-displacement curve at the inflection point. An overview of the evolution of these parameters with the testing temperature before ageing is shown in Fig. 7.

It can be observed that for all binders the same tendency between the different parameters and testing temperatures is found. Changing from a ductile to a brittle state, by decreasing the temperature, both the maximum force needed to start the fracture of the sample (Fig. 7a) and the stiffness increases (Fig. 7c). By definition, the stiffness depends on the shape of the curve because it coincides with the tangent in the inflexion point. However, the work carried out until fracture is obtained from the combination of both, maximum force and stiffness. In all the analysed cases, the fracture work decreased with cooling. Hence, at low temperatures and with stiffer specimens, more maximum force is achieved, but the less work is required until reaching the fracture. It is also shown
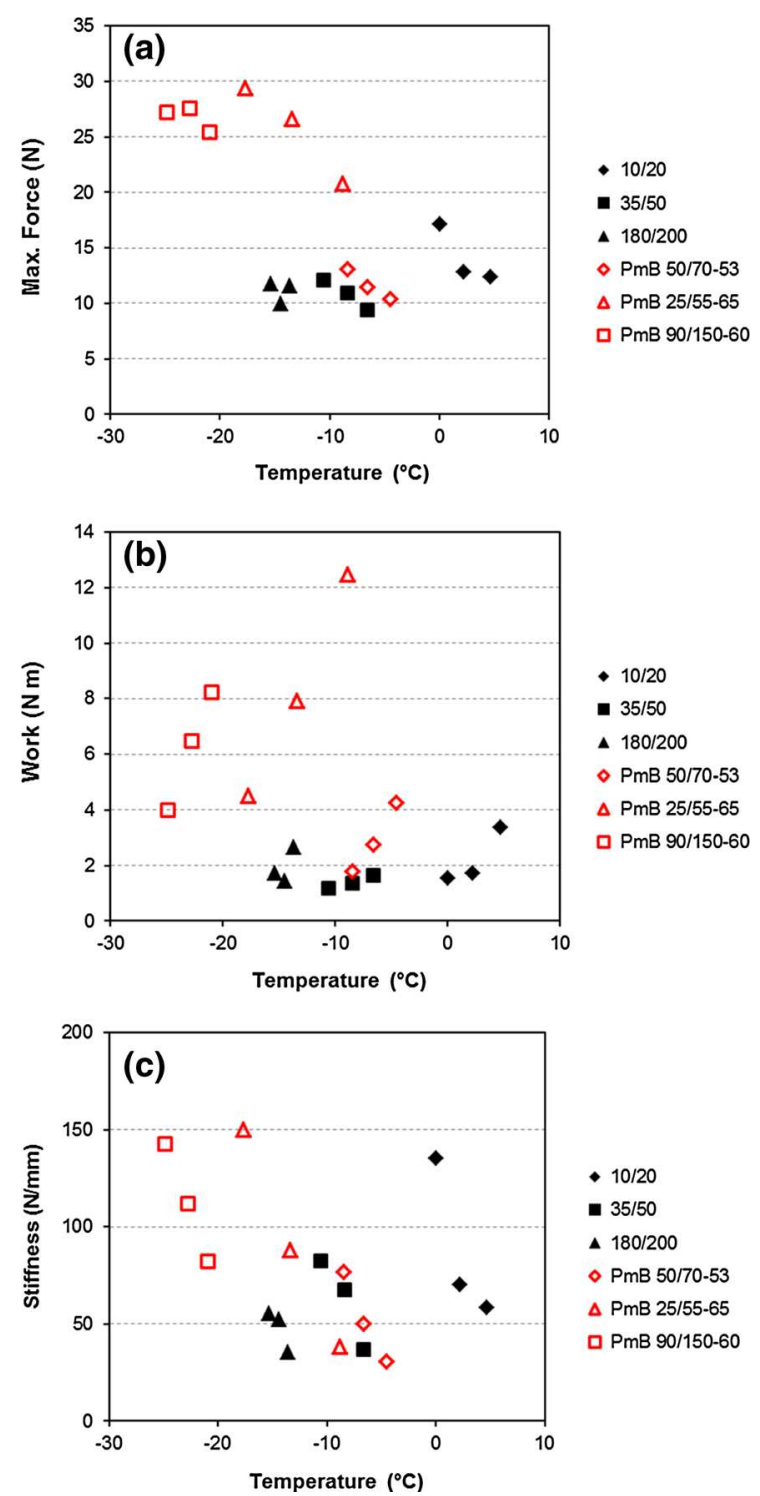

Fig. 7 Temperature influence on maximum force (a), work (b) and initial stiffness (c)

that polymer modified binders needed more force to fracture.

It is important to remark that the maximum force $\left(F_{\mathrm{f}}\right)$ reached is directly related to the critical stress intensity factor $\left(K_{\mathrm{IC}}\right)$ by Eq. (1) with the geometry used in the technical specification [21]:

$K_{\mathrm{IC}}=F_{\mathrm{f},} \times 2377$,

$K_{\text {IC }}\left(\mathrm{N} / \mathrm{m}^{3 / 2}\right)$ is a mechanical parameter that can be only considered at the elastic domain giving a measure of the material strength at the failure point. 

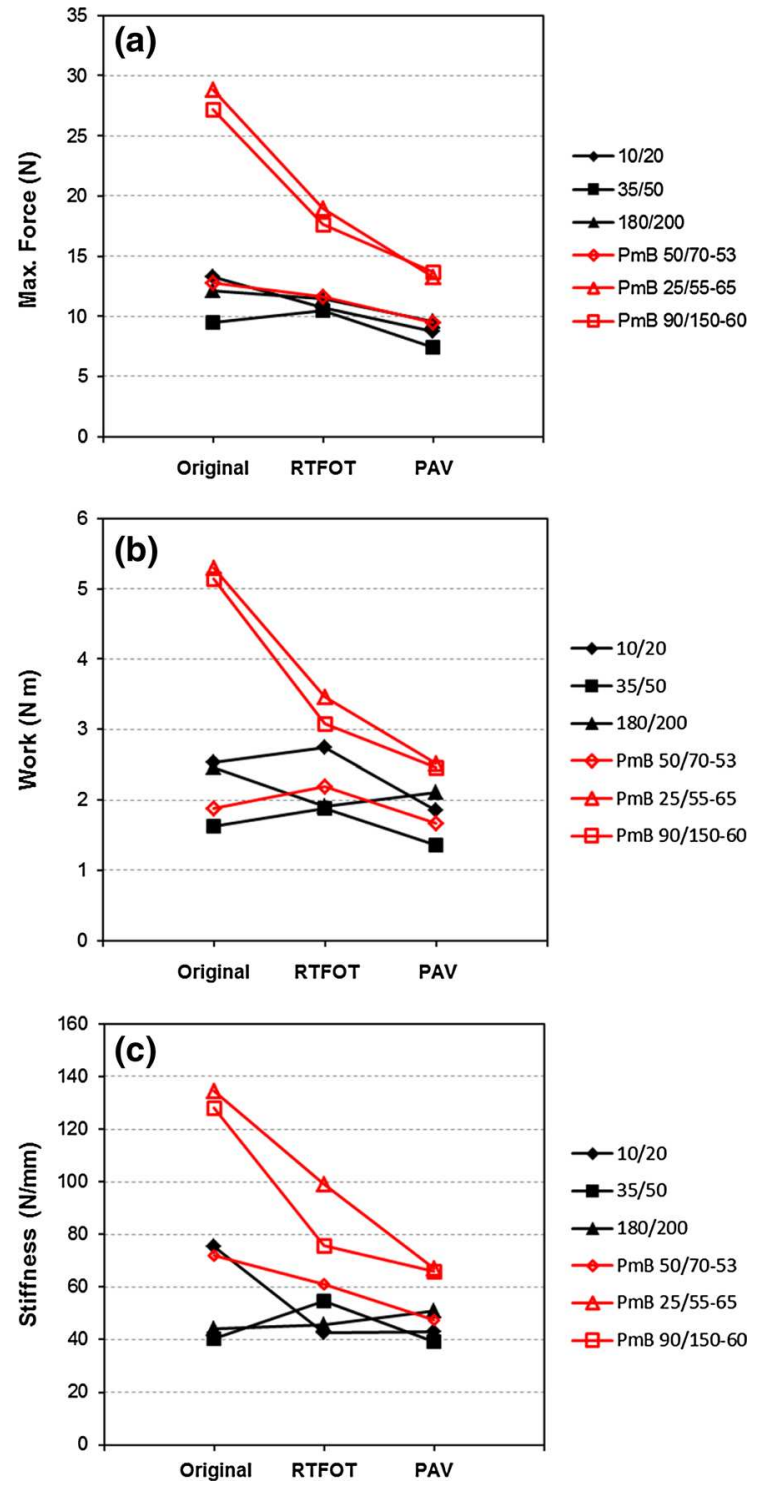

Fig. 8 Influence of ageing on maximum force (a), work (b) and initial stiffness (c)

The influence of ageing on maximum force, fracture work and stiffness at the fracture toughness temperature is shown in Fig. 8. It can be seen that usually after artificial ageing in the laboratory all parameters decrease. This effect seems to be more pronounced on the modified binders with higher differences after ageing. However, the decreases found for the rest of the specimens are lower, remaining almost constant or even slightly increasing after ageing. Again it can be observed that the low temperature properties of $\mathrm{PmB}$ 25/55-65 and $\mathrm{PmB}$
90/150-60 worsen after ageing. In case of unmodified binders, these parameters seem to be unaffected by ageing despite increasing their fracture toughness temperatures.

\section{Conclusions}

In this work, the fracture toughness test FTT for assessing low temperature properties of bituminous binders has been validated. The fracture toughness test is a three point bending test where a beam with a notch in the middle is used to determine the temperature where the transition from ductile to brittle state occurs. Different unmodified and polymer modified bituminous binders at different artificial ageing states were tested. The results demonstrated that, contrary to the conventional methods, the FTT can clearly distinguish between different kinds of binders and ageing states. This is an advantage compare to Fraass breaking point and BBR tests which cause problems mostly in differentiating polymer modified binders. The repeatability of the measurements was found below $2{ }^{\circ} \mathrm{C}$ for all the tested samples. This value can be considered good in comparison with the current values given in the technical specification of the test. However, a remarkably good correlation between fracture toughness temperatures and Fraass breaking points after ageing procedures was found. This result was better for the unmodified than for the polymer modified binders. Considering just classical properties such as softening point and penetration, clear tendencies are not shown since the low temperature behaviour of the bituminous binders is related in a too complex way to their internal structures. Another advantage of the FTT is that it allows studying other parameters directly obtained from the measurements, i.e. the maximum force needed to start the fracture, the work carried out until reaching the maximum load and the initial stiffness at test temperature. The analysis of these parameters allowed quantifying the effect of the ageing on the behaviour of polymer modified asphalt. In addition, it seems that the use of ethanol as cooling fluid did not present any significant influence on the repeatability of the results. However, considering what is reported in other works, it is recommended to carry out further studies for assessing the low temperature behaviour of bituminous binders with other cooling media. 
Acknowledgments This study has been supported by the Swiss Federal Road Office (FEDRO). The corresponding author thanks to the Administration of Science and Technology of Castilla-La Mancha (Spain) for the postdoctoral fellowship cofinanced by European Social Funds within the framework of the Regional Plan of Scientific Research, Technological and Innovation Development (PRINCET).

\section{References}

1. Gubler R, Partl MN, Riedi M, Angst C (2003) Test methods for the behavior of bituminous binders at low temperature. In: Proceedings of 6th RILEM Symposium PTEBM'03, Zurich

2. Isacsson U, Zeng H (1997) Relationships between bitumen chemistry and low temperature behavior of asphalt. Construct Build Mater 11(2):83-91

3. Li X, Marasteanu MO (2006) The role of temperature and binder type on the fracture resistance of asphalt mixture at low temperature. Road Mat Pavement Design 7(3):331-348

4. Kim KW, Kweon SJ, Doh YS, Park T-S (2003) Fracture toughness of polymer-modified asphalt concrete at low temperatures. Can J Civ Eng 30:406-413

5. Champion L, Gerard J-F, Plnache J-P, Martin D, Anderson D (2001) Low temperature fracture properties of polymermodified asphalts relationships with the morphology. J Mat Sci 36:451-460

6. Hoare TR, Hesp SAM (2002) Low-temperature fracture testing of asphalt binders regular and modified systems. Transp Res Rec 1728:36-42

7. CEN 12593 (2007) Bitumen and bituminous binders. Determination of the Fraass breaking point, European Committee for Standardization CEN, Brussels

8. Moriyoshi A, Shen J, Ezawa K, Tomoto T (2005) Comparison of various testing methods for low-temperature properties of asphalts. J Jpn Pet Inst 48(6):336-343

9. CEN 14771 (2005) Bitumen and bituminous binders. Determination of the flexural creep stiffness. Bending Beam Rheometer (BBM), European Committee for Standardization CEN, Brussels

10. Eckmann B, Mazé M, Le Hir Y, Harders O, Gauthier G (2004) Checking low temperature properties of polymer modified bitumen. Is there a future for the Fraass breaking point? In: Proceedings of 3rd Eurobitume Congress, Vienna

11. Edwards WA, Hesp SAM (2006) Compact tension testing of asphalt binders at low temperatures. Transp Res Rec 1962: 36-43

12. Andriescu A, Hesp SAM (2009) Time-temperature superposition in rheology and ductile failure of asphalt binders. Int J Pavement Eng 10(4):229-240

13. Kim H, Partl MN (2010) Development of a Double-Torsion Fracture Test for Bituminous Materials. In: Proceedings of 11th International Conference on Asphalt Pavements (ISAP), Nagoya

14. Hesp S (2004) Development of a fracture mechanics-based asphalt binder test method for low temperature performance prediction. Final report for Highway IDEA Project 84

15. Velasquez R, Bahía H (2013) Critical factors affecting thermal cracking of asphalt pavements: towards a comprehensive specification. Road Mat Pavement Design 14: 187-200

16. Ritchie RO (2011) The conflicts between strength and toughness. Nat Mat 10:817-822

17. Lee NK, Hesp SAM (1994) Low-temperature fracture toughness of polyethylene-modified asphalt binders. Transp Res Rec 1436:54-59

18. Chailleux E, Scholten E, Blomberg T, Hugener M, Gallet T, Büchler S, Lancaster IM, Jones A, Mouillet V, Lorino T (2012) Round robin test of the fracture toughness test for the low temperature properties of bituminous binders. In: Proceedings of 5th Eurasphalt and Eurobitume Congress, Istanbul

19. CEN 12607-1 (2007) Bitumen and bituminous binders. Determination of the resistance to hardening under the influence of heat and air-Part 1: RTFOT method, European Committee for Standardization CEN, Brussels

20. CEN 14769 (2012) Bitumen and bituminous binders. Accelerated long-term ageing conditioning by Pressure Ageing Vessel (PAV), European Committee for Standardization CEN, Brussels

21. CEN TS15963 (2010) Bitumen and bituminous binders. Determination of the fracture toughness temperature by a three point bending test on a notched specimen, European Committee for Standardization CEN, Brussels

22. Chailleux E, Hamon H, Mouillet V (2006) Determination of the low temperature bitumen cracking properties: Fracture mechanics principle applied to a three points bending test using a non-homogeneous geometry. In: Proceedings of 10th International conference on Asphalt Pavement, Québec

23. Bueno M, Hugener M, Partl MN (2013) Fracture toughness aspects for assessing low temperature behaviour of bituminous binders. In: Proceeding of International RILEM Symposium on Multi-Scale Modeling and Characterization of Infrastructure Materials, Stockholm

24. Falchetto AC, Turos MI, Maresteanu MO (2012) Investigation on asphalt binder strength at low temperaturas. Road Mat Pavement Design 13(4):804-816

25. Kliewer JE, Zeng H, Vinson TS (1996) Aging and lowtemperature cracking of asphalt concrete mixtue. J Cold Reg Eng 10(3):134-148

26. CEN 1426 (1999) Bitumen and bituminous binders. Determination of needle penetration, European Committee for Standardization CEN, Brussels

27. CEN 1427 (1999) Bitumen and bituminous binders. Determination of the softening point. Ring and ball method, European Committee for Standardization CEN, Brussels 